\title{
O CONSUMO DOS SERVIÇOS DE CRÉDITO POR IDOSOS DO PROGRAMA MUNICIPAL DE TERCEIRA IDADE DE VIÇOSA, MG
}

\author{
Consumption of credit services by older adults of the Municipal \\ Program for Senior Citizens from Viçosa, MG, Brazil \\ Consumo de servicios de crédito por adultos mayores en el \\ Programa Municipal de Tercera Edad de Viçosa, Brasil
}

\author{
Adriana Miranda de Vasconcelos \\ Universidade Federal de Viçosa, Minas Gerais, Brasil. \\ Mestre pelo Programa de Pós-Graduação em Economia Doméstica da Universidade Federal de Viçosa. \\ E-mail: adriana_vasc@yahoo.com.br
}

\section{Neuza Maria da Silva}

Universidade Federal de Viçosa, Minas Gerais, Brasil.

Professora titular do curso de Economia Doméstica da Universidade Federal de Viçosa. PhD em Economia da Família e do Consumidor pela Purdue University.

E-mail:neuzams@ufv.br

\section{Márcia Barroso Fontes}

Universidade Federal de Viçosa, Minas Gerais, Brasil.

Professora adjunta do curso de Economia Doméstica da Universidade Federal de Viçosa. Doutora em Demografia pela Universidade Federal de Minas Gerais.

E-mail:marciabfontes@gmail.com

RESUMO Este artigo tem por objetivo analisar a forma como ocorre o consumo dos serviços de crédito, verificando valores contratados a título de crédito consignado, limite do cartão de crédito e do crediário por meio de pesquisa quantitativa com 52 idosos participantes de um Programa de Terceira Idade do Município de Viçosa, MG. Verificou-se a autonomia desses quando da contratação do crédito como também a necessidade constante de recorrer a esse tipo de serviço.

PALAVRAS-CHAVE Consumo, Serviço de Crédito, Idosos.

ABSTRACT This article aims to analyze the use of credit services, checking amounts contracted as payroll-deductible loans, credit card limits and credit facilities through a quantitative field research with fifty-two elderly participants of a senior citizen's program in the city of Viçosa, MG, Brazil. We verified the autonomy of these senior citizens when contracting credit as well as their constant need for this type of service.

KEYWORDS Consumption, Credit service, Elderly.

RESUMEN En este texto se pretende analizar cómo es el uso de los servicios de crédito: los valores contratados en forma de préstamos de nómina, los límites de las tarjetas de crédito y las líneas de crédito, mediante investigación de campo cuantitativa con 52 adultos mayores, participantes de un Programa de Tercera Edad de la Ciudad de Viçosa, MG. Se averiguó su autonomía al contratar el crédito, así como la necesidad constante de este tipo de servicio.

PALABRAS CLAVE Consumo, Servicio de Crédito, Anciano. 


\section{INTRODUCÃO}

A expansão do crédito no Brasil se intensificou a partir de 1994 com a estabilização da moeda ocorrida em virtude do Plano Real. Antes desse período tinha-se uma mentalidade voltada para a poupança, em que os consumidores eram caracterizados como seguros, autênticos poupadores. Com a perda da poupança no período do governo Fernando Collor de Melo, com a mudança de postura por parte das instituições financeiras que passaram a facilitar a concessão do crédito e, ainda, com a legislação permitindo a consignação na remuneração dos trabalhadores ou nos benefícios previdenciários, teve-se maior consumo dos serviços de crédito (Alves, 2012).

Para Bauman (2010), a oferta de crédito está relacionada com o modo de vida que a população adquiriu, qual seja, o estilo de vida a "curto prazo". Em tempos remotos era necessário adiar os desejos, economizar para então, adquirir o bem almejado. Com a expansão do crédito, isso não se faz mais necessário, o consumidor pode inverter a ordem: desfrutar agora e pagar depois. Camarano et al. (2014) ao discorrerem sobre as desigualdades na dinâmica demográfica e suas implicações na distribuição de renda no Brasil no período de 1980 e 2010 demonstraram que ao dividir a renda da população em cinco partes iguais foi possível observar que nos trinta anos considerados os idosos ficaram menos pobres, sendo que a proporção da população idosa do estrato de renda mais alta, 17,3\% é semelhante à encontrada na Eslováquia e Eslovênia (17,6\% e 17,8\%, respectivamente). Esses dados comprovam a autonomia financeira do idoso, motivo este que possibilita o uso dos serviços de crédito por estes.

O Ministério da Previdência Social informou que em outubro de 2014 o volume de contratação de empréstimo consignado por aposentados e pensionistas chegou a $\mathrm{R} \$ 3,3$ bilhões, totalizando 841.689 contratos. Pelas estatísticas do referido órgão, ao comparar o mês de outubro com o mesmo mês de 2013, houve um aumento de $11,5 \%$ nos instrumentos contratuais de consignado (Brasil, 2014).

Saliente-se ainda que os idosos, além de serem consumidores do crédito consignado, também estavam aderindo ao uso de cartões de crédito. Segundo pesquisa realizada pela Associação Brasileira das Empresas de Cartões de Crédito e Serviços, em 2009, 52\% das pessoas com mais de 60 anos possuíam pelo menos um cartão de crédito. Já em 2012 esse percentual cresceu para 68\%, demonstrando, assim, a receptividade dos idosos quanto ao uso do crédito na versão cartão de crédito (Gazeta do Povo, 2012).

Por meio do método estado da arte, realizou-se o levantamento bibliográfico sobre as produções acadêmicas que tratavam do consumo na terceira idade. Para tanto, utilizou-se as bases de dados da Capes, SciELO e Google Acadêmico, tendo por critérios estudos realizados no Brasil, no período de 2005 a 2015, que demonstravam no título as palavras "consumo" e "terceira idade". Obteve-se sete resultados, sendo dois do período de 2015, um de 2014, um de 2011, um de 2010, um de 2009 e um de 2008. Esses estudos concentravam-se na área de comunicação, administração e envelhecimento humano. Por meio da leitura dos resumos, verificou-se que os trabalhos das referidas áreas especificavam a análise de propagandas (Araújo et al., 2015; Quezado; Sousa; Matos, 2014), mídias digitais (Bersch, 2009), consumo alimentar (Carneiro, 2011; Boz; Santos; Mendes, 2010; Magdalena; 
Scare; Casanova, 2008) e comportamento de compra (Vasconcelos; Loreto; Silva, 2015).

Considerando os dados expostos, verifica-se que os idosos são consumidores do serviço de crédito, contudo, na literatura acadêmica não foi possível verificar estudos sobre a forma como estes utilizam os serviços de crédito, razão pela qual justifica-se este artigo. Este trabalho tem como principais objetivos verificar o valor médio que os maiores de 70 anos buscavam nos empréstimos consignados; o gasto médio com a utilização do cartão de crédito e do crediário de loja, observar se existia diferença da média dos valores do crédito utilizado entre os gêneros, se havia autonomia quando da tomada de decisão para a contratação dos serviços de crédito, bem como se contratariam novamente o serviço de crédito.

\section{PROCEDIMENTOS METODOLÓGICOS}

A pesquisa se caracterizou como quantitativa, uma vez que se realizou a apuração de dados estatísticos relacionados aos valores contratados no crédito consignado, cartão de crédito e no crediário. A população estudada foi constituída por idosos, do gênero feminino e masculino, moradores da cidade de Viçosa, Minas Gerais, aposentados e/ou pensionistas e, ainda, que estavam em uso de algum tipo de crédito concedido por instituições financeiras ou pelo comércio local. A amostra foi selecionada a partir dos participantes do Programa Municipal de Terceira Idade (PMTI). Para a definição dos participantes deste estudo foram utilizados os seguintes critérios: possuir idade igual ou superior a 60 anos, estar cadastrado no Programa Municipal de Terceira Idade de Viçosa, possuir telefone fixo e estar em uso de algum serviço de crédito ofertado pelas instituições financeiras e/ou pelo comércio.

Os dados foram coletados por meio de elementos fornecidos pelos próprios participantes do estudo, sendo estes obtidos por entrevista, com um roteiro semiestruturado. O contato com os entrevistados ocorreu no período de novembro de 2015 a janeiro de 2016. Todos os participantes assinaram o Termo de Livre Consentimento aprovado com o projeto de pesquisa pelo Comitê de Ética em Pesquisa com Seres Humanos da Universidade Federal de Viçosa sob o parecer CAAE: 44140415.8.0000.5153.

Os dados foram analisados por meio de métodos estatísticos descritivos, para tanto se utilizou o programa Statistical Package for Social Sciences, versão 22. Realizaram-se testes de Mann-Whitney para verificar se existiam diferenças de médias considerando o gênero.

\section{RESULTADOS E DISCUSSÕES}

Constatou-se que $32,7 \%$ dos entrevistados utilizavam o crédito consignado e apenas 1,9\% crédito consignado, carnê de loja e cartão de crédito, conjuntamente (Tabela 1). 
Tabela 1. Tipos de créditos utilizados pelos idosos entrevistados. Viçosa (MG), 2016.

\begin{tabular}{lcc}
\hline \multicolumn{1}{c}{ TIPOS DE CRÉDITO } & FREQUÊNCIA & PERCENTUAL \\
\hline Crédito consignado & 17 & 32,7 \\
\hline Cartão de crédito & 9 & 17,3 \\
\hline Carnê de loja & 9 & 17,3 \\
\hline Consignado/Carnê de loja & 4 & 7,7 \\
\hline Cartão de crédito/Carnê de loja/Consignado & 1 & 1,9 \\
\hline Cartão de crédito/Carnê & 4 & 7,7 \\
\hline Cartão de crédito/Consignado & 8 & 15,4 \\
\hline Total & 52 & 100 \\
\hline
\end{tabular}

Fonte: Dados da pesquisa elaborada pelas autoras.

De acordo com os dados do Relatório de Estabilidade Financeira, divulgado em setembro de 2014 pelo Banco Central, considerando o período de dezembro de 2012 a junho de 2014, o financiamento imobiliário e o crédito consignado foram as modalidades que apresentaram maior participação no crescimento anual do crédito. O referido documento ainda menciona que o cartão de crédito teve participação na ordem de $14 \%$ considerado o período de junho de 2014 (Brasil, 2014).

Comparando os dados da Tabela 1 com os do Relatório de Estabilidade Financeira do Banco Central (2014), tem-se que o crédito consignado também foi o mais utilizado, seguido do cartão de crédito e do carnê de loja. Em relação ao carnê de loja, os dados dessa tabela indicam que os idosos entrevistados utilizavam esse tipo de crédito em porcentagem bem próxima ao da pesquisa realizada pelo Serviço de Proteção ao Crédito em 2014, a qual constatou que 19\% dos pesquisados faziam compras cujo pagamento era feito por meio de carnê de loja (SPC Brasil, 2015). Para uma parte da população brasileira sobretudo a classe C (renda mensal entre $\mathrm{R} \$ 1.064$ e $\mathrm{R} \$ 4.591$ ), não bancarizada e que vive fora dos grandes centros urbanos, os dados do referido órgão indicam que o crediário é a única via para conseguir realizar compras em valores mais altos (SPC Brasil, 2015).

Ao relacionar o tipo de crédito utilizado com a faixa de renda individual dos idosos entrevistados (Tabela 2), constatou-se que aproximadamente $30 \%$ dos entrevistados que utilizavam o crédito consignado recebiam até um salário-mínimo por mês, 35,3\% tinham rendimentos acima de um até três salários-mínimos, e os que recebiam acima de cinco salários-mínimos representavam 35,3\%. De acordo com o Ministério da Previdência (Brasil, 2014), 54,5\% dos empréstimos realizados por aposentados e pensionistas do INSS eram contratados por pessoas que tinham renda até um salário-mínimo. Essa porcentagem é superior à encontrada nesta pesquisa. Contudo, em relação aos que possuíam renda até três salários-mínimos, estes representavam 32,1\%, porcentagem bem próxima da realidade desta pesquisa. 
Tabela 2. Tipo de crédito utilizado pelos idosos de acordo com a faixa de renda. Viçosa (MG), 2016.

\begin{tabular}{|c|c|c|c|c|c|c|}
\hline \multirow{2}{*}{ TIPO DE CRÉDITO } & & \multicolumn{4}{|c|}{$\begin{array}{c}\text { RENDA INDIVIDUAL } \\
\text { (EM SALÁRIOS-MÍNIMOS) }\end{array}$} & \multirow[b]{2}{*}{ TOTAL } \\
\hline & & ATÉ & $\begin{array}{l}\text { ACIMA } \\
\text { DE UM }\end{array}$ & & & \\
\hline \multirow{2}{*}{ Crédito consignado } & Frequência (N) & 5 & 6 & 6 & - & 17 \\
\hline & Porcentagem (\%) & 29,4 & 35,3 & 35,3 & - & 100 \\
\hline \multirow{2}{*}{ Cartão de crédito } & Frequência (N) & - & 4 & 4 & 1 & 9 \\
\hline & Porcentagem (\%) & - & 44,4 & 44,4 & 11,1 & 100 \\
\hline \multirow{2}{*}{ Carnê de loja } & Frequência (N) & 4 & 4 & 1 & - & 9 \\
\hline & Porcentagem (\%) & 44,4 & 44,4 & 11,1 & - & 100 \\
\hline \multirow{2}{*}{$\begin{array}{l}\text { Consignado/Carnê } \\
\text { de loja }\end{array}$} & Frequência (N) & 3 & 1 & - & - & 4 \\
\hline & Porcentagem (\%) & 75 & 25 & - & - & 100 \\
\hline \multirow{2}{*}{$\begin{array}{l}\text { Cartão de crédito/Carnê } \\
\text { de loja/Consignado }\end{array}$} & Frequência (N) & - & - & - & 1 & 1 \\
\hline & Porcentagem (\%) & - & - & - & 100 & 100 \\
\hline \multirow{2}{*}{ Cartão de crédito/Carnê } & Frequência $(\mathrm{N})$ & 3 & 1 & - & - & 4 \\
\hline & Porcentagem (\%) & 75 & 25 & - & - & 100 \\
\hline \multirow{2}{*}{$\begin{array}{l}\text { Cartão de crédito/ } \\
\text { Consignado }\end{array}$} & Frequência (N) & 3 & 2 & 2 & 1 & 8 \\
\hline & Porcentagem (\%) & 37,5 & 25 & 25 & 12,5 & 100 \\
\hline \multirow{2}{*}{ Total } & Frequência $(\mathrm{N})$ & 18 & 18 & 13 & 3 & 52 \\
\hline & Porcentagem (\%) & 34,6 & 34,6 & 25 & 5,8 & 100 \\
\hline
\end{tabular}

Fonte: Dados da pesquisa elaborada pelas autoras.

Quanto ao cartão de crédito, observou-se que os idosos que possuíam renda até um salário-mínimo não utilizavam esse tipo de serviço de crédito, mas usavam o carnê de loja e o crédito consignado. Contudo, quando verificado o uso de cartão de crédito com o carnê de loja, os idosos com renda de até um salário-mínimo representaram $75 \%$ dos usuários desses serviços. Os dados da Tabela 2 confirmam a informação do SPC Brasil (2015) no sentido de o crediário ser usado, principalmente, por classe mais baixa. Os idosos com renda entre um a três saláriosmínimos representaram 88,8\% dos entrevistados usuários do carnê de loja.

Avaliando os percentuais totais, quanto menor a renda, mais se utiliza o serviço de crédito, isso porque os idosos que recebiam até um salário-mínimo e os maiores de 60 anos que percebiam benefícios previdenciários acima de um até três salários-mínimos representavam 34,6\% e os com renda superior a cinco salários-mínimos representavam 5,8\% dos usuários do serviço de crédito (Tabela 2).

Analisando a relação entre o tipo de crédito utilizado e o gênero, observa-se que em relação ao crédito consignado, o número de homens e mulheres que contrataram esse serviço era bem semelhante. Esse fato também foi divulgado pelo Ministério da Previdência (Brasil, 2014) ao dispor que, em setembro de $2014,53,4 \%$ da contratação do crédito consignado era realizada por mulheres e $46,6 \%$ por homens. Já em relação ao uso de cartão de crédito, os homens o utilizavam em conjunto com o crédito consignado, ou seja, na amostra deste estudo não foram encontrados homens usando exclusivamente o cartão de crédito (Gráfico 1). Dados da pesquisa realizada pelo Instituto Serasa Consumidor sobre Consultas do Sistema Financeiro - Especial Mulher, demonstraram que as mulheres solicitavam cartões de crédito mais do 
que os homens, sendo que em 2011, 57\% da demanda por esse tipo de serviço de crédito era feita por elas (SPC Brasil, 2012).

Já em relação ao crediário, o SPC Brasil (2015) indicou que 50\% dos homens entrevistados não utilizavam o crédito para fazer compras. Pelo Gráfico 1 constata-se que o número de homens que utilizavam o crediário era bem inferior ao de mulheres.

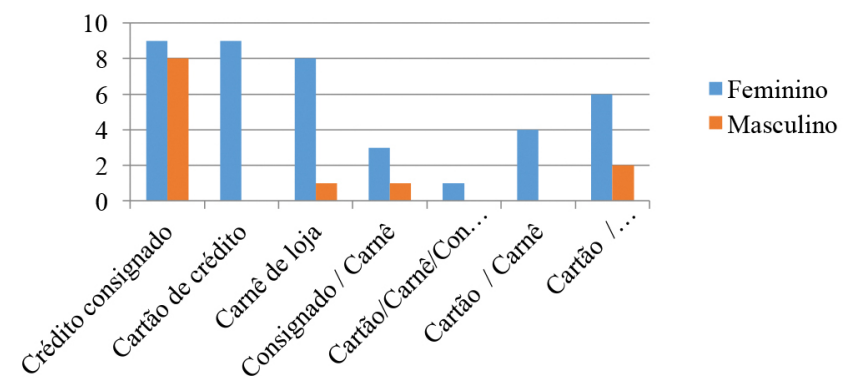

Gráfico 1. Utilização do serviço de crédito de acordo com o gênero dos idosos. Viçosa (MG), 2016.

Fonte: Dados da pesquisa elaborada pelas autoras.

O Gráfico 2 demonstra que em relação a faixa etária e o tipo de crédito utilizado, os idosos com idade acima de 75 até 85 anos foram os que menos recorrem ao serviço de crédito. Esse fato é explicado por Neri (2007) que por meio de seus estudos verificou que a medida que a idade dos idosos aumenta, cai a efetivação por serviços de crédito. Por outro lado, as pessoas de 60 até 65 anos foram as que mais utilizaram o serviço de crédito.

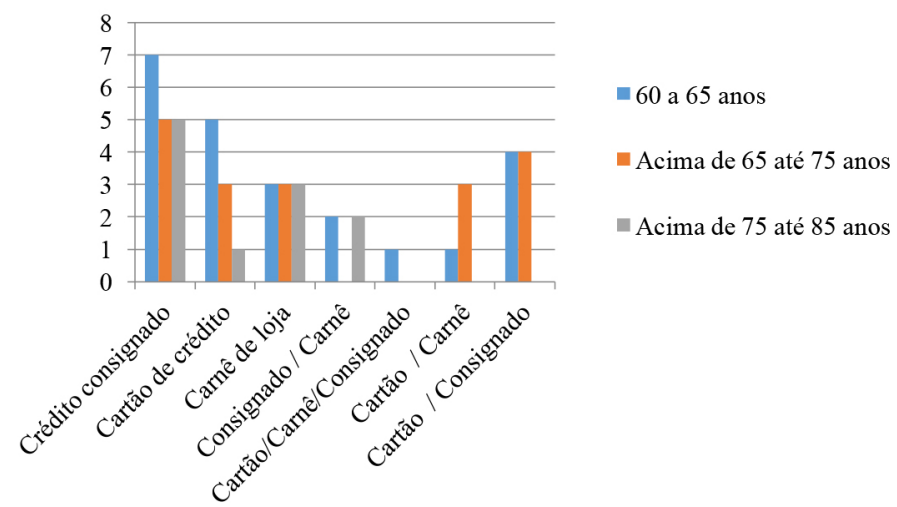

Gráfico 2. Utilização do serviço de crédito por faixa etária dos idosos. Viçosa (MG), 2016. Fonte: Dados da pesquisa elaborada pelas autoras.

Ao serem questionados sobre a influência sofrida ao contratar algum serviço de crédito, $69,2 \%$ dos idosos responderam que não foram influenciados por ninguém e 30,8\% disseram que sofreram influência principalmente dos filhos, de gerentes de instituições financeiras e/ou de telemarketing e do cônjuge (Tabela 3). 
Tabela 3. Influência sofrida pelos idosos entrevistados quando da contratação de algum serviço de crédito. Viçosa (MG), 2016.

\begin{tabular}{lcc}
\hline $\begin{array}{l}\text { INFLUÊNCIA SOFRIDA NA } \\
\text { CONTRATAÇÃO DO CRÉDITO }\end{array}$ & $\begin{array}{c}\text { FREQUÊNCIA } \\
(\mathbf{N})\end{array}$ & $\begin{array}{c}\text { PERCENTUAL } \\
(\%)\end{array}$ \\
\hline Cônjuge & 2 & 3,8 \\
\hline Filhos & 4 & 7,7 \\
\hline Gerentes de instituições financeiras & 4 & 7,7 \\
\hline Propaganda de televisão/rádio & 1 & 1,9 \\
\hline Telemarketing & 4 & 7,7 \\
\hline Funcionário de loja & 1 & 2,0 \\
\hline Total & 16 & 30,8 \\
\hline
\end{tabular}

Fonte: Dados da pesquisa elaborada pelas autoras.

Da análise do tipo de crédito e a influência sofrida na contratação desses serviços, verificou-se que os serviços relacionados ao cartão de crédito foram os que sofreram maior influência de terceiros (Gráfico 3). Contudo, convém ressaltar que os idosos pesquisados apresentaram autonomia, uma vez que predominou a vontade própria quando da pactuação do serviço de crédito, principalmente, o serviço de crédito consignado. Essa realidade também foi encontrada por Souza et al. (2014) em seus estudos sobre o crédito consignado utilizado pelos idosos de Não-Me-Toque, Rio Grande do Sul. Esses autores afirmaram que os idosos declararam que não houve influência de terceiros, mesmo entre aqueles que utilizaram o consignado para auxiliar um parente.

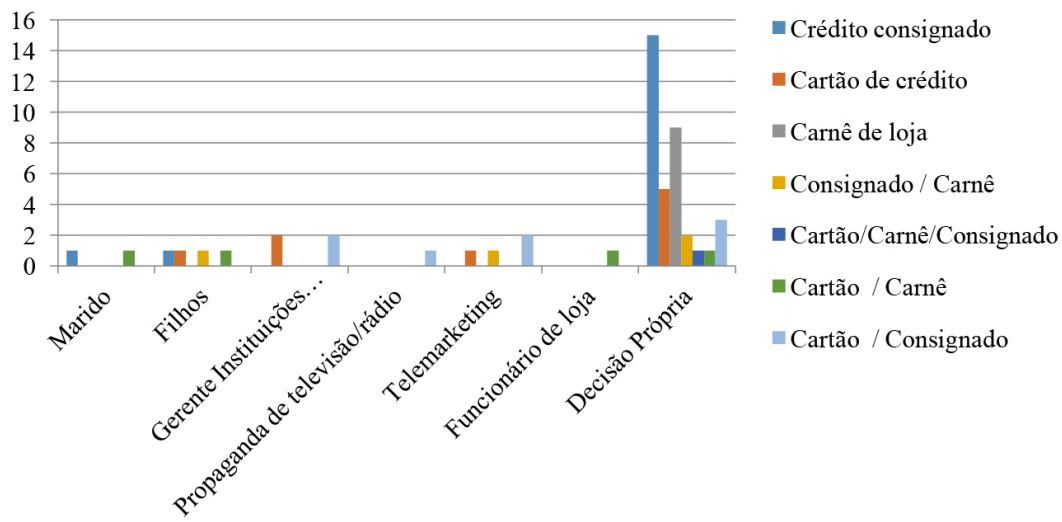

Gráfico 3. Tipo de crédito e influência sofrida pelos idosos na contratação do serviço. Viçosa (MG), 2016.

Fonte: Dados da pesquisa elaborada pelas autoras.

Questionados sobre a possibilidade de nova contratação do serviço de crédito, $80,8 \%$ dos idosos responderam que contratariam, sendo que os tipos de crédito mais citados em caso de nova contratação foram o crédito consignado, seguido pelo cartão de crédito e pelo carnê de loja (Tabela 4). De acordo com Bauman (2010), vive-se em uma época em que não é possível mais existir sem o uso do serviço de crédito, pois não se adia mais o prazer, os consumidores sempre buscam o crédito para a realização dos desejos imediatos e, ainda para o referido autor, viver a crédito cria dependência. A afirmação supra de Bauman (2010) pode justificar o alto percentual dos idosos que contratariam novamente algum serviço de crédito. 
Tabela 4. Possibilidade de nova contratação dos serviços de crédito pelos idosos. Viçosa (MG), 2016.

\begin{tabular}{lcc}
\hline \multicolumn{1}{c}{ TIPO DE CRÉDITO QUE CONTRATARIA } & $\begin{array}{c}\text { FREQUENCIA } \\
(\mathbf{N})\end{array}$ & $\begin{array}{c}\text { PORCENTUAL } \\
(\%)\end{array}$ \\
\hline Não contrataria & 10 & 19,2 \\
\hline Crédito consignado & 13 & 25,1 \\
\hline Cartão de crédito & 12 & 23,1 \\
\hline Carnê de loja & 12 & 23,1 \\
\hline Consignado/Carnê de loja & 2 & 3,8 \\
\hline Cartão de crédito/Carnê de loja & 2 & 3,8 \\
\hline Adiantamento do décimo terceiro salário & 1 & 1,9 \\
\hline Total & 52 & 100 \\
\hline
\end{tabular}

Fonte: Dados da pesquisa elaborada pelas autoras

Ao cruzar os dados referentes ao tipo de crédito utilizado e o serviço de crédito que contrataria em uma eventual oportunidade, observa-se pela Tabela 5 que os idosos, em sua grande maioria, usariam o mesmo tipo de crédito que já utilizavam. Apenas dois idosos apontaram outro tipo de crédito diferente do que usava quando da realização deste estudo. Esse fato possibilita questionar se os idosos tinham conhecimento dos tipos de crédito disponíveis no mercado ou se, por hábito, contratavam sempre o mesmo serviço.

Quanto aos valores contratados a título de crédito consignado, constatou-se que em relação às medidas de tendência central o montante mínimo foi de $\mathrm{R} \$ 1.000$, o máximo de $\mathrm{R} \$ 33.000$, sendo o valor médio de $R$ \$ 8.230, mediano de $R \$ 5.000$. O valor que mais se repetiu na contratação do empréstimo foi de $\mathrm{R} \$ 5.000$, representando $11,5 \%$ do valor contratado pelos idosos entrevistados, com desvio padrão de 8.290, assimetria de 1,57 e curtose de 1,74. Comparando os resultados deste estudo com a pesquisa desenvolvida por Souza e Moretto (2014) sobre os motivos que levam os idosos do município de Não-Me-Toque (RS) a contratarem o crédito consignado, percebeu-se que estes solicitaram empréstimos no montante médio de $\mathrm{R} \$ 3.900$, valor inferior ao contratado pelos idosos participantes do Programa Municipal de Terceira Idade de Viçosa (MG). Acredita-se que essa diferença refere-se ao montante da renda percebida pelos idosos, uma vez que no estudo de Souza e Moretto (2014), a maioria dos idosos recebia até um salário-mínimo e nesta pesquisa apenas 34,6\% recebiam até um salário-mínimo e 65,4\% acima de um salário-mínimo. Ao realizar a análise estatística exploratória dos dados estatísticos do valor contratado a título de crédito consignado, verificou-se anormalidade, por apresentar assimetria (média, mediana e moda possuem valores diferentes).

Para melhor compreender se existia diferença estatística entre o valor mediano do montante contratado a título de crédito consignado e o gênero, considerando a anormalidade dos dados, realizou-se o teste de média não paramétrico para amostra independentes denominado de Mann-Whitney, tendo formulado as seguintes hipóteses: (1) $\mathrm{H}_{0}=$ não existe diferença entre os valores contratados a título de crédito consignado por idosos e idosas e (2) $\mathrm{H}_{1}=$ existe diferença entre os valores contratados a título de crédito consignado por idosos e idosas.

Ao realizar o teste, o resultado obtido indicou que a significância foi maior que 0,05 , ou seja, rejeita-se $\mathrm{H}_{1}$ e aceita $\mathrm{H}_{0}$, chegando a conclusão de que não existe diferença entre os valores medianos do montante contratado a título de crédito consignado por idosos e idosas. Esse resultado e seus detalhes podem ser vistos na Gráfico 4 e no Quadro 1. 


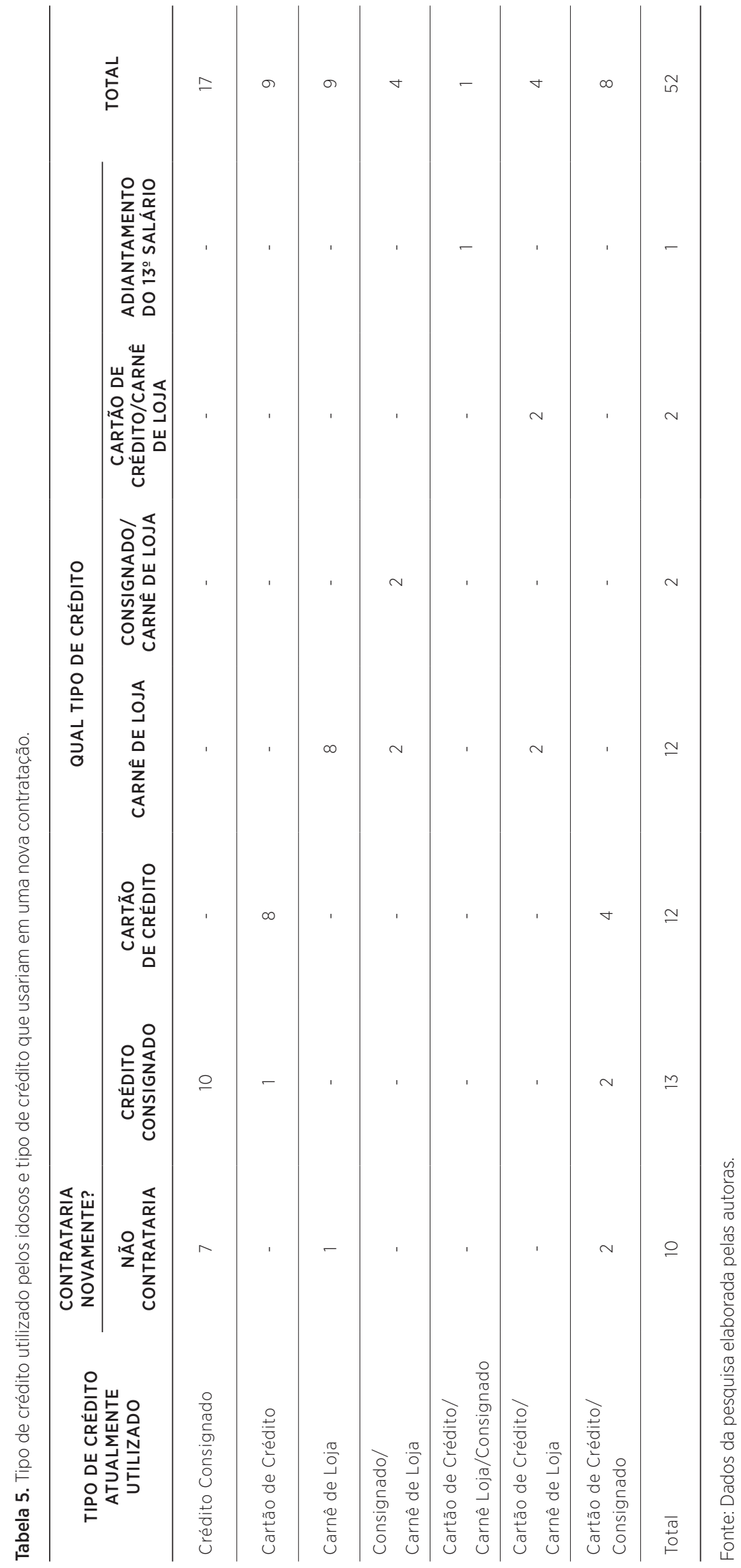


Teste U de Mann-Whitney de amostras independentes

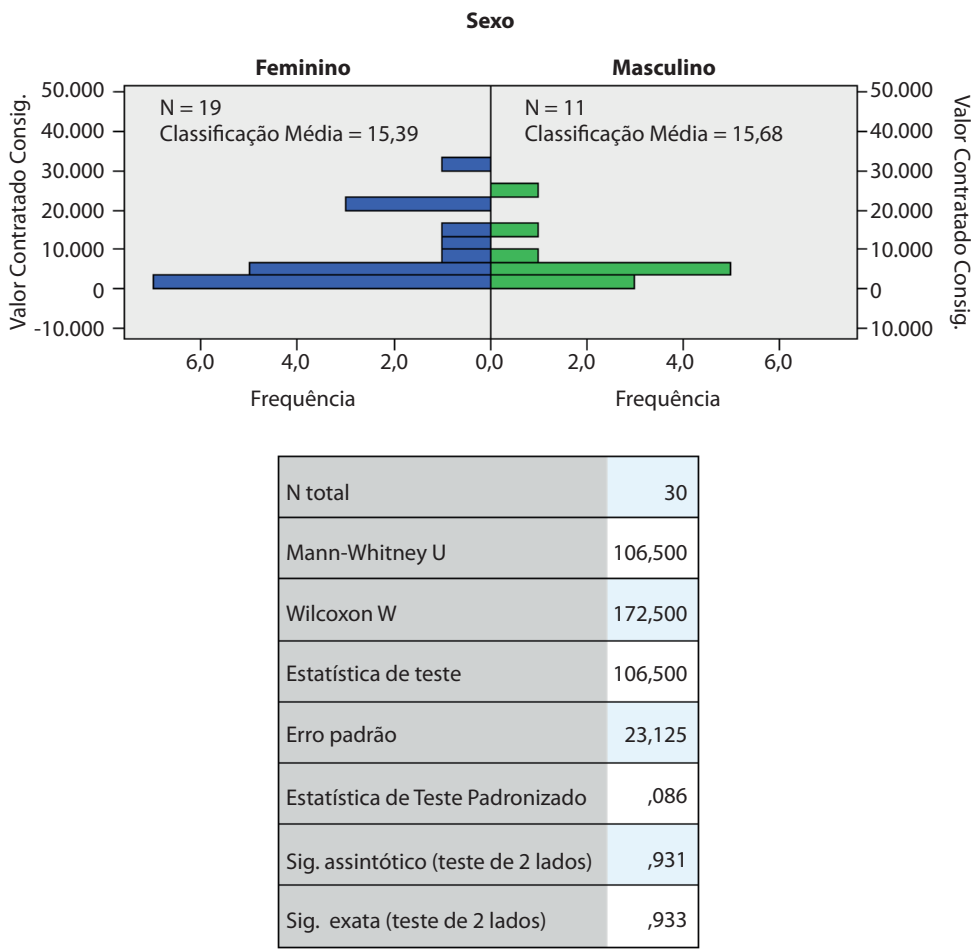

Gráfico 4. Teste de Mann-Whitney para valor contratado de acordo com o gênero dos entrevistados. Viçosa (MG), 2016.

Quadro 1. Resumo do teste de hipótese para valor contratado a título de crédito consignado e gênero. Viçosa (MG), 2016.

\begin{tabular}{|lcccc|}
\hline & HIPÓTESE NULA & TESTE & SIG. & DECISÃo \\
\hline 1 & $\begin{array}{c}\text { A distribuição do valor } \\
\text { contratado a título de crédito } \\
\text { consignado é a mesma entre } \\
\text { a categoria de gênero. }\end{array}$ & $\begin{array}{c}\text { Teste U de } \\
\text { Mann-Whitney } \\
\text { de amostras } \\
\text { independentes }\end{array}$ & ,933 & $\begin{array}{c}\text { Reter a } \\
\text { hipótese nula. }\end{array}$ \\
\hline $\begin{array}{l}\text { São exibidas } \\
\text { significâncias } \\
\text { assintóticas. O nível de } \\
\text { significância é } 0,05 .\end{array}$ & & & \\
\hline
\end{tabular}

Fonte: Dados da pesquisa elaborada pelas autoras.

Ao analisar o Gráfico 4 observa-se que tanto as mulheres como os homens contratavam mais empréstimo consignado no intervalo de 0 a 10.000. Contudo, as idosas faziam mais empréstimos no valor mais próximo a $\mathrm{R} \$ 5.000$, enquanto os idosos buscavam valores próximos a $\mathrm{R} \$ 10.000$, o que pode ter influenciado a existência da não diferença entre os valores contratados a título de crédito consignado entre idosos e idosas por meio da compensação de valores.

Com o intuito de se obter informação sobre o valor que foi cedido aos idosos a título de limite do cartão de crédito, questionou-se qual valor contratado para uso no cartão de crédito e verificou-se que o montante mínimo foi de $\mathrm{R} \$ 480$ máximo de $\mathrm{R} \$ 6.000$, média de $\mathrm{R} \$ 1.977,72$, mediana de $\mathrm{R} \$ 2.000$, moda de $\mathrm{R} \$ 2.000$, com desvio padrão de 1251,84, variância de 1567113,63 , assimetria de 1,55 e curtose de 3,89. Para esse tipo de crédito não foi realizado o teste de média do valor cedido a título de limite para 
uso do cartão de crédito e gênero porque, conforme o Gráfico 1, apenas idosas usavam exclusivamente esse serviço.

Nesta pesquisa foi possível verificar o valor dispendido pelos idosos quando do pagamento mensal do carnê de loja, o prazo para quitação das prestações, bem como o valor total das compras realizadas nessa modalidade de crédito. Constatou-se que os idosos realizavam compras no crediário no valor médio de $\mathrm{R} \$ 559,94$, mediano de $\mathrm{R} \$ 389$, sendo o valor mais comum dos produtos adquiridos $\mathrm{R} \$ 100$, este representando aproximadamente $6,0 \%$ do valor das aquisições. O valor mínimo da compra foi de $\mathrm{R} \$ 95$, máximo de $\mathrm{R} \$ 2.000$ desvio padrão de 509,61, variância de 259702,64, assimetria de 1,49 e curtose de 2,45.

A análise estatística exploratória dos dados sobre o valor da compra feita no crediário demonstrou anormalidade, por apresentar assimetria.

Com o intuito de verificar se existia diferença entre o valor dos produtos adquiridos por meio do carnê de loja e o gênero, realizou-se o teste de média não paramétrico de Mann-Whitney, sendo formuladas as seguintes hipóteses: (1) $H_{0}=$ não existe diferença entre os valores dos produtos adquiridos por meio do carnê de loja por idosos e idosas e (2) $\mathrm{H}_{1}=$ existe diferença entre os valores dos produtos adquiridos por meio do carnê de loja por idosos e idosas.

O resultado desse teste demonstrou que a significância foi maior que 0,05 , ou seja, rejeitou-se $\mathrm{H}_{1}$ e aceitou $\mathrm{H}_{0}$, chegando à conclusão de que não existe diferença entre os valores medianos do montante contratado para uso do cartão de crédito e a faixa etária dos idosos (Gráfico 5 e Quadro 2).

Teste U de Mann-Whitney de amostras independentes

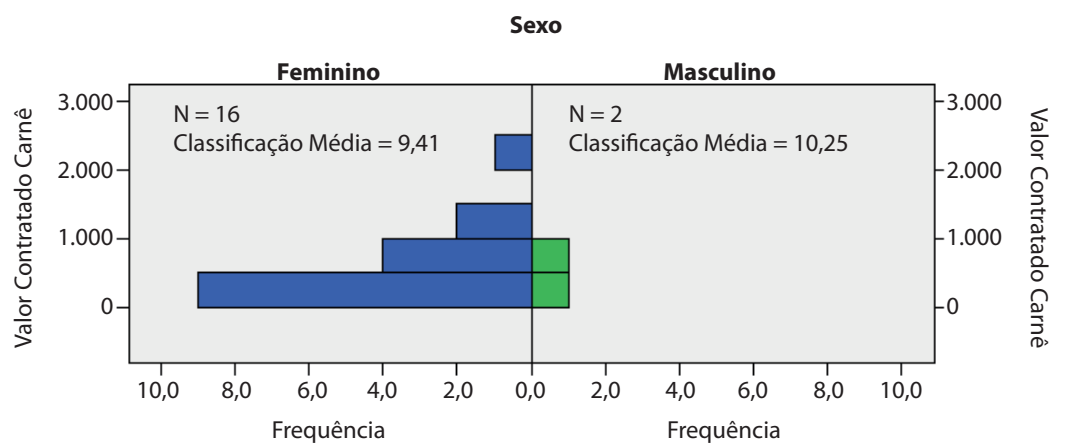

\begin{tabular}{|lr|}
\hline N total & 18 \\
\hline Mann-Whitney U & 17,500 \\
\hline Wilcoxon W & 20,500 \\
\hline Estatística de teste & 17,500 \\
\hline Erro padrão & 7,092 \\
\hline Estatística de teste Padronizado &, 211 \\
\hline Sig. assintótico (teste de 2 lados) &, 832 \\
\hline Sig. exata (teste d 2 lados) &, 837 \\
\hline
\end{tabular}

Gráfico 5. Teste de Mann-Whitney para valor do produto adquirido no carnê de loja de acordo com o gênero dos idosos. Viçosa (MG), 2016. 
Quadro 2. Resumo do teste de hipótese para valor contratado - carnê de loja e gênero.

\begin{tabular}{|ccccc|}
\hline HIPÓTESE NULA & TESTE & SIG. & DECISÃo \\
\hline 1 & $\begin{array}{c}\text { A distribuição do valor } \\
\text { contratado a título de carnê } \\
\text { de loja é a mesma entre a } \\
\text { categoria de gênero. }\end{array}$ & $\begin{array}{c}\text { Teste } U \text { de } \\
\text { Mann-Whitney } \\
\text { de amostras } \\
\text { independentes }\end{array}$ & ,837 & $\begin{array}{c}\text { Reter a } \\
\text { hipótese } \\
\text { nula. }\end{array}$ \\
\hline $\begin{array}{c}\text { São exibidas } \\
\text { significâncias } \\
\text { assintóticas. O nível } \\
\text { de significância é } \\
\text { 0,05. }\end{array}$ & & & \\
\hline
\end{tabular}

Fonte: Dados da pesquisa elaborada pelas autoras.

Ao analisar o Gráfico 5 percebe-se que se considerarmos a faixa de valor contratado no carnê de loja por homens e mulheres ( 0 a 1.000) esta se encontra em igualdade para ambos os gêneros, diferindo apenas o número de mulheres e de homens que usavam este serviço. Assim como na pesquisa do SPC Brasil (2015), o número de homens idosos usuários do crediário foi inferior ao de mulheres idosas que usavam esse tipo de serviço.

\section{CONSIDERAÇÕES FINAIS}

Este estudo possibilitou compreender que o serviço de crédito é uma realidade presente na vida dos idosos pesquisados. Eles utilizavam o crédito de forma recorrente e indicaram intenção de continuar utilizando-o. Ademais, o recebimento de benefícios de pensões e aposentadorias pelos idosos faz que estes sejam vistos pelo mercado e pela mídia como consumidores potenciais desse tipo de serviço, razão pela qual verifica-se o número crescente de propagandas a eles dirigidas, divulgando a facilidade de obtenção do crédito.

É interessante destacar que os entrevistados demonstraram autonomia quando da tomada de decisão ao contratar o serviço de crédito. Contudo, não demonstraram estar informados sobre os outros tipos de crédito que não aqueles que já utilizavam.

Os testes estatísticos de média realizados não demonstraram diferença entre as médias dos valores contratados a título de crédito consignado e crediário entre idosos e idosas. Esse fato nos leva a crer que homens e mulheres buscam estatisticamente os mesmos valores ao utilizar os serviços de crédito. Verificou-se ainda que homens e mulheres idosos utilizavam em igualdade o serviço de crédito, todavia, o cartão de crédito e o crediário eram usados mais por mulheres idosas. Sendo assim, conclui-se que é necessário ampliar as informações relacionadas aos diferentes tipos de crédito que podem ser contratados pelos idosos como as vantagens e desvantagens de cada um dos serviços, taxas de juros e encargos incidentes sobre o crédito, penalidades em caso de rescisão contratual como também estratégias para lidar com a renda e o orçamento doméstico após a contratação do crédito. Essas medidas têm por objetivo possibilitar aos idosos fazer melhores escolhas em relação ao serviço a ser contratado, fatos estes que impedem o superendividamento, a restrição ao uso do crédito e uma melhor utilização pelos idosos desse tipo de serviço. 


\section{REFERÊNCIAS}

ALVES, A. A. C. Aspectos jurídicos do empréstimo consignado em benefícios do INSS. Conteúdo Jurídico, Brasília, DF, 2012. Disponível em: <http://bit.ly/2noBERW>. Acesso em: 14 jan. 2016.

ARAÚJO, F. F. et al. O consumidor de terceira idade na primeira década do século XXI: uma análise da propaganda dirigida a idosos. Revista Administração em Diálogo, São Paulo, v. 17, n. 1, p. 54-85, jan./fev./mar. 2015. Disponível em: <http://bit.ly/2nolJlz>. Acesso em: 12 out. 2016.

BAUMAN, Z. Vida a crédito: conversas com Citali Rovirosa-Madrazo. Trad. Alexandre Werneck. Rio de Janeiro: Zahar, 2010.

BERSCH, L. J. Internet e terceira idade: consumo e efeitos em usuários do extremo Oeste do Paraná. 2009. Dissertação (Mestrado em Comunicação Social) - Departamento de Comunicação Social, Pontifícia Universidade Católica do Rio Grande do Sul, Porto Alegre, 2009.

BOZ, C.; SANTOS, J. S.; MENDES, K. G. Descrição do índice de massa corporal e do padrão do consumo alimentar das integrantes de uma Universidade da terceira idade no interior do RS. Revista Brasileira de Ciências do Envelhecimento Humano, Passo Fundo, v. 7, n. 2, p. 229-243, maio/ago. 2010. Disponível em: <http://bit.ly/2naybED>. Acesso em: 15 out. 2016.

BRASIL. Banco Central do Brasil. Pesquisa sobre endividamento. 2014. Disponível em: <http://bit.ly/2nabTmG>. Acesso em: 16 jan. 2015.

BRASIL. Ministério da Previdência Social. Consignado: operações somam R\$ 3,3 bilhões em setembro. 2014. Disponível em: <http://bit.ly/2orMrds>. Acesso em: 26 nov. 2015.

CAMARANO, A. A. et al. Desigualdades na dinâmica demográfica e suas implicações na distribuição de renda no Brasil. In: CAMARANO, A. A. (Org.). Novo regime demográfico: uma nova relação entre população e desenvolvimento? Rio de Janeiro: Ipea, 2014.

CARNEIRO, I. A. Terceira idade e consumo: experiência de consumo alimentar da classe C. 2011. 221 f. Tese (Doutorado em Administração) - Universidade Federal de Lavras, Lavras, 2011.

GAZETA DO POVO. Cartão é coisa de jovem. E de idoso. Jun. 2012. Disponível em: <http:// bit.ly/2nbsCXk>. Acesso em: 20 fev. 2016.

MAGDALENA, H. Z.; SCARE, R. F.; CASANOVA, A. C. P. Hábitos de consumo e atributos valorizados na compra de leite pelo público da terceira idade. In: CONGRESSO DA SOCIEDADE BRASILEIRA DE ECONOMIA, ADMINISTRAÇÃO E SOCIOLOGIA RURAL, 46., 2008, Rio Branco. Anais... Rio Branco: SOBER, 2008. Disponível em: <http://bit.ly/2oayZLq>. Acesso em: 15 out. 2016.

NERI, M. C. Renda, consumo e aposentadoria: evidências, atitudes e percepções. Ensaios Econômicos, Rio de Janeiro, n. 663, dez. 2007. Disponivel em: <http://bit.ly/203GG9J>. Acesso em: 21 jan. 2016.

QUEZADO, I.; SOUSA, E. C.; MATOS, F. R. N. Perfil de consumo e autopercepção do idoso em anúncios televisivos. In: CONGRESSO INTERNACIONAL COMUNICAÇÃO E CONSUMO, 4., 2014, São Paulo. Anais... São Paulo: PPGCOM ESPM, 2014. Disponível em: <http://bit. ly/2nbt7kf>. Acesso em: 12 out. 2016.

SERVIÇO DE PROTEÇÃO AO CRÉDITO - SPC BRASIL. Dois em cada dez brasileiros têm alguma compra no crediário. 2015. Disponível em: <http://bit.ly/2noydL9>. Acesso em: 4 abr. 2016.

Mulheres são maioria por demanda de cartão de crédito. Estudo sobre consultas do sistema financeiro - especial mulheres. 2012. Disponível em: <http://bit.ly/2nazdjX>. Acesso em: 1ำ abr. 2016.

SOUZA, B. O.; MORETTO, C. F. Entre a razão e a emoção: a tomada de crédito consignado pelos idosos. Revista Brasileira de Ciências do Envelhecimento Humano, Passo Fundo, v. 11, n. 1, p. 75-88, 2014. Disponível em: <http://bit.ly/2nawF5F>. Acesso em: 21 jan. 2016.

VASCONCELOS, A. M.; LORETO, M. D. S.; SILVA, A. O. O consumo das mulheres idosas participantes da oficina de artesanato de um programa de terceira idade em Viçosa Minas Gerais. In: CONGRESSO INTERNACIONAL DE ENVELHECIMENTO HUMANO, 4., 2015, Campina Grande. Anais... Campina Grande: Universidade Estadual da Paraíba, 2015. Disponível em: <http://bit.ly/2nayNdJ>. Acesso em: 12 out. 2016. 